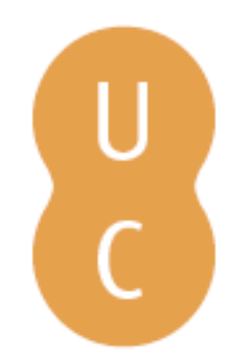

\title{
Rompalina
}

Os impasses sobre a liberdade de imprensa no pensamento utilitarista
Autor(es): $\quad$ Camponez, Carlos
Publicado por: Imprensa da Universidade de Coimbra
URL
persistente: URI:http://hdl.handle.net/10316.2/31703
DOI: $\quad$ DOI:http://dx.doi.org/10.14195/978-989-26-0204-2_7

Accessed : $\quad$ 26-Apr-2023 10:39:26

A navegação consulta e descarregamento dos títulos inseridos nas Bibliotecas Digitais UC Digitalis, UC Pombalina e UC Impactum, pressupõem a aceitação plena e sem reservas dos Termos e Condições de Uso destas Bibliotecas Digitais, disponíveis em https://digitalis.uc.pt/pt-pt/termos.

Conforme exposto nos referidos Termos e Condições de Uso, o descarregamento de títulos de acesso restrito requer uma licença válida de autorização devendo o utilizador aceder ao(s) documento(s) a partir de um endereço de IP da instituição detentora da supramencionada licença.

Ao utilizador é apenas permitido o descarregamento para uso pessoal, pelo que o emprego do(s) título(s) descarregado(s) para outro fim, designadamente comercial, carece de autorização do respetivo autor ou editor da obra.

Na medida em que todas as obras da UC Digitalis se encontram protegidas pelo Código do Direito de Autor e Direitos Conexos e demais legislação aplicável, toda a cópia, parcial ou total, deste documento, nos casos em que é legalmente admitida, deverá conter ou fazer-se acompanhar por este aviso.

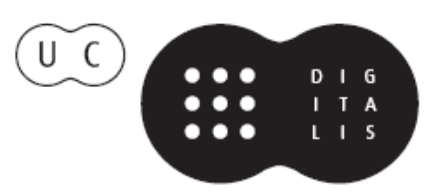


Carlos Camponez

Ana Teresa Peixinho

Coordenação

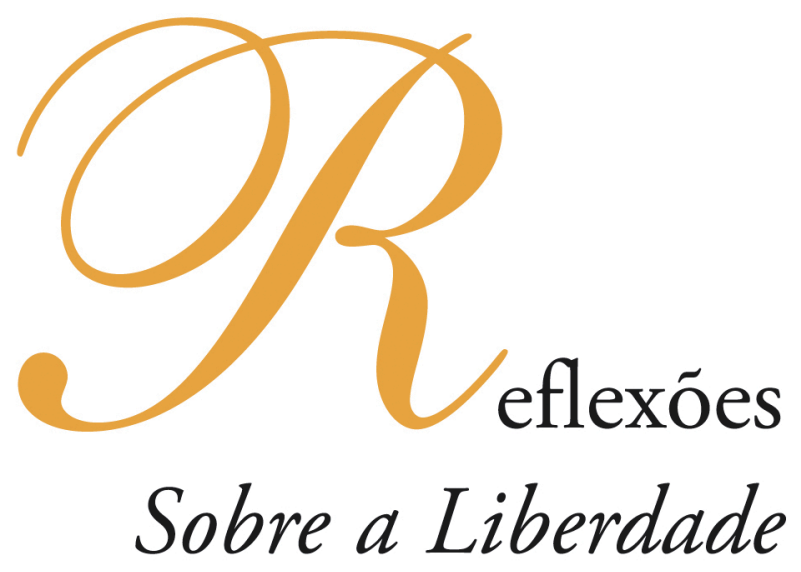

150 anos da obra de John Stuart Mill

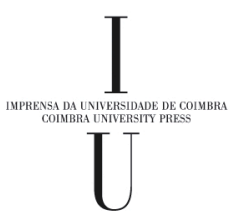




\section{OS IMPASSES SOBRE A LIBERDADE DE IMPRENSA NO PENSAMENTO UTILITARISTA}

\section{Carlos Camponez}

No presente artigo, propomo-nos reflectir acerca dos impasses sobre a liberdade de imprensa no pensamento utilitarista. Fá-lo-emos procurando confrontar os pensamentos de Jeremy Bentham, em «Sobre a liberdade de imprensa e de discussão pública» $(1821)^{47} \mathrm{e}$ em "Garantias contra o abuso do poder» (1822-1823), e de John Stuart Mill, em Sobre a Liberdade (1859). De acordo com o ponto de vista que sustentaremos aqui, a dissensão que consideramos existir entre estes dois pensadores utilitaristas representa um marco importante numa evolução que, por razóes não apenas filosóficas, foi distinguindo cada vez mais a função social de liberdade de imprensa da liberdade individual de expressão, embora sem nunca chegar a separá-las definitivamente.

\section{Sobre a Liberdade: a nova Areopagítica}

Na perspectiva da liberdade de expressão e da liberdade de imprensa, o livro de John Stuart Mill Sobre a Liberdade, publicado em 1859, representa o culminar de dois séculos de pensamento sobre um tema decisivo da história. Com efeito, estamos perante um texto que, em certa medida, é a reactualização, em termos modernos, da discussão iniciada por John Milton, em 1644, com a publicação de Areopagitica, e desenvolvida pelo pensamento iluminista acerca da liberdade individual, da liberdade de expressão e da liberdade de imprensa. Uma primeira leitura dos livros Areopagitica e Sobre a Liberdade não deixará de notar a semelhança de argumentos utilizados num e noutro texto. Este aspecto terá levado alguns comentadores de Mill - tanto admiradores como detractores - a referirem-se ao Sobre a Liberdade como a nova Areopagitica (O’Rourke, 2001: 145 e nota 5 na p. 205). De facto, o seu pensamento retoma muitos dos argumentos miltonianos sobre a liberdade de expressão, a liberdade de imprensa e o fim da censura prévia. Só para recordarmos alguns deles, podemo-nos referir à discussão pública como um modelo essencial de formação das opiniôes; ao reconhecimento do estatuto do erro como elemento inextricável da verdade e de reafirmação da própria verdade; à razáo como elemento fundamental de ligação do sujeito à verdade; enfim, à defesa da liberdade de expressão como uma dimensão intrínseca de realização da natureza humana.

Obviamente que a identificação destas semelhanças exigiria uma abordagem mais consentânea com uma leitura do pensamento dos autores, nomeadamente procurando en-

$47 \mathrm{Na}$ realidade, trata-se de quatro cartas abertas escritas às Cortes espanholas, em 1820, que deveriam ser traduzidas por M. Mora, chefe de redacção de El Constitucional, na esperança que seriam publicadas antes dos debates sobre o projecto-de-lei sobre a liberdade de expressão e de discussão pública. Porém, isso não chegou a acontecer porque as cartas acabaram por se extraviar, chegando ao conhecimento público apenas em 1821, depois de as leis, contra as quais estas cartas se dirigiam, terem sido aprovadas. 
tender se aquilo que hoje podemos ler no texto de Milton corresponde exactamente ao seu pensamento, há mais de três séculos e meio. Para além disso, como refere Kevin C. O’Rourke, a herança radical de John Stuart Mill permitiu-lhe ter uma identidade que ele próprio julgava ser completamente oposta à de Milton e que - nas suas palavras -, com todo o seu republicanismo, teria a alma de um fanático, de um déspota e de um tirano (Apud O'ROURKE, 2001: 159).

A discussão acerca do Sobre a Liberdade como uma nova Areopagitica não deve fazer-nos esquecer os elementos inovadores da abordagem de Mill. De facto, os argumentos miltonianos sobre a liberdade de pensar, a liberdade de escrever e a liberdade de publicar, bem como a defesa do fim da censura prévia sofreram uma importante reactualização no contexto do pensamento liberal do séc. XIX e do denominado segundo liberalismo. Como refere Pierre Manent, este «segundo liberalismo» tem por principal tarefa absorver o choque causado pelos acontecimentos e as ideias da Revoluçáo Francesa, bem como compreender essa aparente contradição que resultou do facto de as ideias liberais, durante o período revolucionário, terem sido geradoras de mais perseguição e opressão do que durante o período anterior, no final do Ancien Regime (Manent, 1987: 173). Segundo defendemos noutro texto (Camponez, 2010: cap. V), este é um elemento que perturba o pensamento liberal do século XIX e que não deixará de contribuir, de forma importante, para uma compreensão mais problematizadora da liberdade de expressão e da liberdade de imprensa, que até então eram vistas como o corolário uma da outra. Lentamente, em especial no velho continente, esta visão acabará por evoluir no sentido de distinguir estas duas realidades, quer no plano dos princípios, quer no plano do Direito.

\section{Bentham: a imprensa como um tribunal da opiniáo pública}

O conceito contemporâneo de imprensa como instrumento importante do escrutínio público, fundamental para as democracias contemporâneas, é em muito devedor do pensamento utilitarista, em particular de Jeremy Bentham. Nele, se fundam as concepçôes que inspiraram a visão da imprensa e dos jornalistas como quarto-poder ou os cães-de-guarda dos cidadãos face aos governos e à administração pública. A noção de quarto-poder e de cão-de-guarda das instituiçôes democráticas fez o seu caminho a partir da ideia central que Bentham atribuía à divulgação e circulação das informaçóes acerca da vida pública. Para o filósofo inglês, só o escrutínio público é capaz de limitar a tendência para os abusos inerentes ao exercício do poder sem controlo. Com efeito, Bentham tem uma opiniáo essencialmente negativa do poder, em particular dos seus detentores. Ele considera que os ministros do governo são pessoas que, à imagem do que fariam todas as outras no seu lugar, «aproveitarão todas as ocasióes para sacrificarem o interesse da comunidade aos seus interesses particulares» (Bentham, 2001ª :58-59). Para Bentham, o abuso do poder, mais do que uma questâo de ética política, resulta da própria natureza humana. Diz-nos ele a este propósito:

«(...) sendo a natureza humana o que é, qualquer pessoa a quem se dá um qualquer poder (...) está certamente em condiçôes de, nesse próprio dia, pensar sobre a forma de perpetuar todos os malefícios nunca anteriormente por ela ousados; e a menos que esteja limitada pelo medo do que o público possa pensar ou fazer, é provável que ela ponha em execuçáo os seus planos, a partir do dia seguinte» (Idem). 
Neste âmbito, a divulgação pública das questóes políticas desempenha um papel de vigilância e escrutínio do poder (Splichal, 2002: 59). Mais do que as reunióes públicas, essa função de controlo é desempenhada pela imprensa, equiparada a um tribunal oficioso, isto é, o tribunal da opinião pública. A imprensa entendida como o tribunal da opinião pública representa no pensamento de Bentham muito mais do que uma mera alegoria. No seu texto «Garantias contra o abuso do poder» (1822-1823), ele estabelece um claro paralelismo entre os tribunais oficiais e o papel atribuído à imprensa em Inglaterra. Esse papel seria o de 1) atender reclamaçôes e queixas; 2) ouvir as respostas da defesa; 3) ouvir, "arrancar», juntar e conservar os testemunhos; 4) ouvir, escutar ou ler os argumentos das partes envolvidas ou dos seus advogados; 5) formar uma opinião sobre os argumentos em presença, julgá-los e tirar deles as ilaçôes correspondentes para depois; 6) exprimi-los; 7) imprimi-los; 8) difundi-los; e, finalmente, 9) proceder de modo a que os julgamentos efectuados e as ilaçóes retiradas produzam efeito (Bentham, 2001 $:$ 148).

Para Bentham, fazem parte do tribunal de opinião todos quantos se interessam pelos assuntos públicos, entendidos como matérias que dizem respeito a cada um e a todos os membros pertencentes a uma comunidade. Este tribunal é pensado à luz e semelhança de uma comunidade composta por quatro tipos fundamentais de pessoas: os que apenas tomam a palavra; os que tomam a palavra e lêem; os que não só falam e lêem, mas também escrevem; e, finalmente, os que, fazendo tudo isto, também imprimem e publicam (Bentham, 2001 ${ }^{\mathrm{b}}$ : 145).

Esta comunidade está por sua vez organizada por vários sub-comités, os mais importantes dos quais são, por ordem de importância: os de «subintendência geral», constituídos pelos editores, chefes de redacção, colaboradores, leitores e clientes em geral; os da «administração judicial», compostos por pessoas que acompanham as questôes de interesse público e formam sobre eles uma opiniáo; e os religiosos, que agregam a comunidade de crentes, bem como os seus líderes.

Bentham defende a existência de um grande número de jornais, com uma circulação tanto mais vasta quanto possível, uma vez que eles são considerados o principal instrumento para o funcionamento da opinião pública. O jornal, melhor do que qualquer outra forma de imprensa (panfletos, livros, etc.), era considerado como o único meio capaz de garantir um acompanhamento regular dos acontecimentos (Bentham, 2001 ${ }^{\text {b: }}$ 130). Para além disso, no seu entender, nenhuma outra produção impressa poderia rivalizar com o jornal na forma de publicitação dos assuntos públicos, assumindo uma dimensão cívica e pedagógica incontornável:

«Abrindo o jornal, cada leitor vai à procura do tema que lhe interessa mais. Mas enquanto ele se dedica a esta busca, passam-lhe sob os olhos todo o tipo de assuntos. Pouco a pouco, o aspecto estranho e detestável destes outros temas esbate-se e o leitor familiariza-se com cada um deles. Mesmo supondo que ele deixa regularmente de lado os assuntos que de todo nâo lhe interessam e para os quais nem sequer olha, o seu interesse por aqueles a que não é totalmente indiferente desperta, apesar de tudo, a pouco e pouco» (Bentham, 2001 ${ }^{\mathrm{b}}$ : 132).

A importância da imprensa faz com que ela deva estar ao serviço da «maior felicidade da maioria», enquanto único princípio de acção social admissível (Bentham, 2001': 139). Esta concepção é em tudo compatível com a noção de quarto poder da imprensa, cuja expressão é atribuída a Edmund Burke quando se referia à galeria reservada aos jornalistas para assis- 
tirem aos debates do parlamento britânico (Splichal, 2002: 59). Mas o grande contributo desta visão foi permitir, no final do séc. XIX, a construção de uma ideologia acerca do jornalismo, visto como quarto poder ou como cão-de-guarda dos governos e da administração. Ela influenciou os próprios paradigmas de investigação e da teoria da comunicação, que legitimaram a ideologia profissional do jornalismo, com base na existência de funçóes «universais» que os media deveriam desempenhar na sociedade. Essa dimensáo escrutinadora e de serviço público impôs-se como poderoso conceito que estruturou o próprio jornalismo, a ponto de se constituir, nas palavras de Peter Braestrup, numa autêntica «teologia pública» dos jornalistas americanos (Apud Goodwin, 1993: 306).

Parece-nos, no entanto, que nâo podemos atribuir esta visão instrumental do jornalismo unicamente a Bentham. Autores como Stephen Ward referem que todas as formas de jornalismo, no séc. XVIII, contêm no seu seio um potencial de esclarecimento, informação e liberdade (Ward, 2004: 160), não sendo apenas uma forma de expressão individual por outros meios, escritos ou impressos.

No entanto, o investigador esloveno, Slavo Splichal, no confronto que faz sobre o pensamento de Bentham e Mill, sublinha a importância que uma certa visão utilitarista exerceu no final do séc. XVIII e durante o séc. XIX, ao ponto de marcar profundamente o próprio jornalismo moderno.

Este aspecto parece-nos relevante na medida em que, não obstante alguns princípios normativos já antes atribuídos à imprensa, a ênfase de um certo utilitarismo dado ao papel instrumental do jornal acabou por constituir uma dimensão relativamente nova, comparativamente ao pensamento iluminista acerca da liberdade de expressão e da liberdade de imprensa. Splichal chega mesmo a defender que a racionalidade e o papel da crítica que o pensamento iluminista atribuía à liberdade de escrever e de imprimir estão secundarizados e quase completamente ausentes da ideia de publicitação em Bentham (Splichal, 2002: 59). Em seu entender, a visão benthamiana sobre a função dos jornais como escrutinadores independentes do poder político e do Parlamento reduz as relaçóes de poder aos actores institucionalizados, directamente envolvidos no processo legislativo, negligenciando outros agentes de poder na sociedade, em particular, as pessoas comuns. Escreve ainda Splichal:

«[em Bentham] o aspecto referente ao debate racional tem apenas uma importância secundária; o carácter "crítico» da publicidade (e.g., no sentido de uma oposição ao governo) está quase ausente; e a ideia racionalista da liberdade humana não existe de todo» (Idem).

No entanto, não podemos deixar de notar que, como afirma Bentham, a publicitação surge como um conceito muito próximo do de opiniáo pública, ainda que não seja propriamente um sinónimo (Bentham, 2001를 108). Como vimos, a opinião pública funciona à maneira de um tribunal, onde o papel crítico não deixa de estar presente, embora aquilo com que Bentham parece estar preocupado seja operacionalizar uma certa ideia de imprensa e de jornalismo como instrumento que responda às exigências de uma opinião pública informada e actuante. De facto, como afirma no seu texto sobre a liberdade de imprensa e de expressão, a «sagesse aproxima-se mais da perfeição quando dispomos de meios gerais de informação (...) do que quando esses meios estão ausentes» (Bentham, $\left.2001^{\mathrm{a}}: 53\right)$. 


\section{O utilitarismo «iluminado» de Mill}

Esta concepção acerca da liberdade de expressão e do papel da imprensa é bastante diferente da de John Stuart Mill cujo pensamento, neste aspecto, parece estar mais na linha da tradição iluminista do que na da filosofia utilitarista de Bentham. O próprio Mill acaba por nos explicar a razão fundamental desta dissensão. Nas suas próprias palavras, Bentham concebe o homem como um ser destituído de capacidade de prosseguir, como um fim válido por si, uma acção desinteressada, razão pela qual conceitos como consciência, princípio, rectidão e dever resultam mais do amor-próprio do que de uma vontade de um sujeito moral. Num contexto em que toda e qualquer acção dos sujeitos esteja marcada pelo interesse pessoal, ou seja, na concepção utilitarista, a realização do seu próprio prazer, só é possível limitar a conduta individual por via do receio das sançóes, sejam elas provenientes da lei, da religião ou da opinião pública (Mill, 1999: 30). Essa é a razão pela qual a imprensa assume mais um carácter de vigilância dos sujeitos detentores do poder do que de um potencial crítico e de formação de uma racionalidade da vida pública, questáo que, no pensamento de Bentham, parece bem mais secundarizada do que na tradição iluminista e liberal.

A desconfiança em assentar um projecto social em princípios morais pode ajudar-nos a compreender a forte crítica que Bentham fez à Declaração dos Direitos do Homem e do Cidadão de 1791 e de 1795, considerando que ela traz a marca das paixóes egoístas e das paixôes hostis que, por mais necessárias que elas sejam à existência de cada indivíduo ou à sua segurança, são na realidade os grandes inimigos da paz pública.

A descrença de Bentham no carácter desinteressado e estritamente moral dos sujeitos leva-o a alimentar uma profunda desconfiança de princípio sobre o sentido das palavras ${ }^{48}$, chamando, nomeadamente, a atenção para as armadilhas que elas podem esconder. Perante tão radical posicionamento face aos princípios éticos e morais do ser humano e, por consequência, das sociedades, a questão que se coloca é pois a de se saber como viabilizar um projecto comum sem uma filosofia das leis, das instituiçóes e dos valores.

Como explica Mill, a filosofia de Bentham aplica-se mais propriamente à regulação dos bens materiais como condição para assegurar o bem-estar do maior número de pessoas, do que a um projecto moral emancipador dos sujeitos e das sociedades. Talvez também por isso, a forma que Bentham encontrou para melhor alcançar o desiderato de bem-estar tenha sido o do exercício do poder da maioria e do sufrágio universal, não se preocupando com algumas questôes qualitativas dessa realização.

Porém, John Stuart Mill parece ter uma visão mais complexa do bem-estar, distinguindo entre prazeres inferiores e superiores e entre fins secundários da moralidade - sobre os quais considera ser possível um consenso - e os fins últimos ou os fundamentos da moral, sobre os quais é mais difícil estabelecer acordos, exigindo também um saber mais profundo dos sujeitos implicados na discussão (Mill, 1999: 39).

Nestes aspectos, Mill distancia-se de Bentham: numa visão mais optimista sobre a capacidade da acçáo desinteressada dos sujeitos; na recusa de uma concepção redutora do

48 Exemplo disso é o comentário que Bentham faz a propósito da expressão «ordem pública» constante no art. $^{\circ} 10$ da Declaração de 1791: «A liberdade de publicaçáo, no que se refere às opiniōes, com ou sem excepção, seria muito conveniente que fosse estabelecida, mas que só o é de uma forma muito precária num artigo assim formulado. "Perturbar a ordem pública: o que quer isso dizer? Luís XVI não teria hesitado em admitir um artigo formulado nestes termos no seu código» [BENTHAM, 2007: 69]. 
princípio do bem-estar aos aspectos materiais ${ }^{49}$; e na rejeição da ideia de atribuir às maiorias o critério último do que esse bem-estar possa significar.

A forma como Mill vê a utilidade, no seu sentido mais amplo, «baseado nos interesses permanentes das pessoas enquanto seres em desenvolvimento» (Madeira, 2006: XIX), faz apelo à necessidade de um sistema crítico capaz de fazer evoluir o próprio conceito utilitarista de bem. Para que isso seja possível, torna-se necessário retomar alguns princípios que estavam na base da defesa da liberdade de expressão e da liberdade de imprensa, tal como foram sendo formulados por Milton e aprofundados pelos iluministas.

\section{Maioria, individualismo e liberdade}

O pensamento iluminista sublinha a livre circulação das ideias como um elemento fundamental de estruturação da opinião e da racionalidade públicas, sobre as quais assenta a legitimidade da soberania política. Rousseau chamou a essa racionalidade pública vontade geral, que se manifestaria através do exercício de uma democracia directa do povo, embora nunca se tivesse preocupado em pensar num modelo destinado a operacionalizar essa mesma vontade (Splichal, 2002: 90). Já em Kant, a livre circulação das ideias é uma condição indispensável do próprio uso público da razão. Este representa uma forma específica de comunicação deliberativa que implica um conhecimento dos processos de exercício político e de cidadania. Esta é a razão pela qual Kant atribui tanta importância à liberdade de escrever, considerando-a como o paladino ${ }^{50}$ da liberdade do povo.

Assim, se no pensamento utilitarista de Bentham a publicitação, na qual os jornais desempenham um papel crucial, tem uma função instrumental de vigilância e de limitação dos abusos do governo, em Kant o uso público da razão mais do que instrumento é o próprio procedimento que permite reconciliar política e legitimidade, ou seja, assumir a política de um ponto de vista moral (Splichal, 2002: 111-112). Em termos kantianos, isto significa que os procedimentos de divulgação pública das ideias e, em particular, da liberdade de imprensa, não representam apenas um meio, mas são, em si mesmo, um fim, enquanto conceito transcendental do direito público, baseado nos cidadãos, na dignidade e numa soberania moral.

O princípio de que qualquer tipo de interdição da divulgação das ideias constitui um entrave ao progresso é um conceito que inspirou o pensamento iluminista e que se reflectiu

49 Diz Mill a este respeito: «É indiscutível que um ser cujas capacidades de prazer são baixas tem uma maior possibilidade de vê-las inteiramente satisfeitas; e um ser superiormente dotado sentirá sempre que qualquer felicidade que possa procurar é imperfeita, tendo em conta a maneira como o mundo é constituído. Mas ele pode aprender a suportar as imperfeiçóes da sua felicidade, se são de todo em todo suportáveis; e elas não o farão invejar o ser que, na verdade, não tem consciência das imperfeiçôes, mas unicamente porque náo sente, de modo algum, o bem que essas imperfeiçóes limitam. É melhor ser um ser humano insatisfeito do que um porco satisfeito; um Sócrates insatisfeito do que um idiota satisfeito. E se o idiota ou o porco têm opinião diferente, é porque apenas conhecem o seu lado da questão. A outra parte da comparação conhece ambos os lados» [MILL, 2005: 54].

50 Uma expressão que encontramos em John Trenchard e Thomas Gordon, sob o pseudónimo de Cato. Na $15^{\text {a }}$ carta, de Fevereiro de 1720, [John TRENCHARD e Thomas GORDON, (1995), «Of freedom of speech: That the same is inseparable from public Liberty", in Cato's Letters - Or Essays on liberty, civil and religious, and other important subjects, vol. I, Indianapolis, Liberty Fund, p. 114] e numa das intervenções de Mirabeau, nos Estados Gerais, nas vésperas da Revolução Francesa [MIRABEAU, (1992), De la Liberté de la Presse - 1788, Caen, Centre de Philosophie Politique et Juridique de L’Université de Caen, p. 420]. 
na própria concepçáo sobre a liberdade de expressão e de imprensa. Essa concepção encontramo-la igualmente em John Stuart Mill que, na linha do pensamento iluminista, defende a ideia da liberdade intelectual como um domínio que não está sob a dependência dos outros e que náo deve ser objecto de qualquer interferência, nomeadamente - e na senda do que pensava também, a este propósito, Alexis de Tocqueville - do poder da maioria.

As questóes levantadas em torno do papel das maiorias na determinação da vontade colectiva são certamente um tema candente no pensamento de meados do séc. XIX e reflectem a inquietação acerca do clima de terror gerado durante a Revolução Francesa que, como referimos atrás, tanto preocupou o pensamento do denominado segundo liberalismo. A preocupação com este tema faz com que Mill faça avançar o debate relativamente aos iluministas. Como já aqui vimos, Kant considera a liberdade de escrever como o paladino da liberdade política dos povos. Mas Mill, sem pôr em causa este princípio, tem, no entanto, uma opiniāo bem mais ambivalente. Por um lado, ele vê na imprensa algo que pode actualizar a antiga ágora dos gregos. Mas, por outro lado, não deixa de considerar que os jornais representam a submissão dos indivíduos relativamente às massas (Splichal, 2002: 143). Para além disso, como refere Splichal, para Mill a liberdade de imprensa reconhecida aos jornais só em parte contribui para a disseminação de ideias que realmente interessam à sociedade e, nalguns casos, promovem mesmo a mediocridade em vez de a prevenir (Splichal, 2002: 144). Nesse sentido, ela não seria sequer fundamental para assegurar a liberdade individual, como se poderia provar com o caso de outros países europeus onde existiam leis mais restritivas do que as existentes na Inglaterra no domínio da imprensa, sem que isso impedisse a realização da autonomia dos sujeitos. Mais do que a liberdade de imprensa, tal como a entendemos hoje, o que está em causa é, pois, a possibilidade de realização do próprio projecto iluminista da razão pública e da liberdade dos sujeitos. Neste domínio, Mill, sem ser kantiano, parece bem mais próximo de Kant do que da corrente utilitarista onde ele próprio se inseria (Splichal, 2002: 131). Contrariamente ao que acontecia com Bentham, para Mill, a questão fundamental não reside apenas em assegurar a divulgação das ideias, como uma forma de controlo da administração pública, mas antes no modo de permitir melhores escolhas, através do reforço dos mecanismos de mediação da comunicação. Para além disso, ele não concorda totalmente com o papel que Bentham atribui à maioria, em particular no que se refere às incidências sobre as liberdades individuais. Enquanto Bentham está particularmente preocupado em limitar o poder político, visto como o poder de uns poucos sobre a vontade dos restantes, Mill analisa esta questão de uma forma muito mais alargada, não deixando de incluir a própria sociedade nas formas de tirania contra a liberdade individual (Mill, 1997: 13). Com efeito, o princípio da maioria continua a persistir numa forma de pensar o poder da sociedade subjugada aos interesses egoístas de classe (Mill, 1999: 39) - antes o poder de alguns, agora o poder da maioria - sem necessariamente contribuir decisivamente para o progresso geral da sociedade, entendido aqui num sentido amplo e enquanto um projecto inacabado, cuja evolução depende do processo crítico proporcionado pela liberdade de pensar, de falar e de escrever de cada um dos sujeitos (Mill, 1997: 21).

A visão crítica de Mill sobre o poder e a irracionalidade das maiorias levá-lo-ão a distanciar-se também da ideia de Bentham que atribuía aos jornais um papel decisivo para o controlo do poder. Como refere a este propósito Slavko Splichal, Mill considerava mesmo que a penny press, que constituiu um marco importante para a massificação e industrialização da imprensa, promovia a mediocridade, em vez de a prevenir (Splichal, 2002: 148). 
O olhar crítico sobre o papel das maiorias levá-lo-ão mesmo a defender a protecção das ideias minoritárias ao afirmar que se qualquer de «duas opiniôes tiver mais argumentos que a outra, para ser, não apenas tolerada, mas encorajada e apoiada, é esta que estará, numa determinada altura e num dado local, em minoria. Essa é a opiniáo que, de momento, representa os interesses descorados, o lado do bem-estar humano que corre o perigo de obter menos do que lhe é devido" (Mill, 1997: 52).

Esta problemática constitui um dos aspectos sensíveis da filosofia de Mill e que esbarra nessa sempre difícil tarefa de conseguir compatibilizar os objectivos gerais da sociedade com os projectos de realização da liberdade de cada um dos seus sujeitos. Este projecto é tanto mais sensível quanto ele é susceptível de pôr em causa o próprio projecto utilitarista, na medida em que, para Mill, a busca do prazer náo se mede apenas numa perspectiva quantitativa, mas também qualitativa. Neste sentido, o poder das maiorias em determinarem o bem-estar imediato pode ser entendido como uma ameaça a esse objectivo mais elevado de alcançar a excelência moral e cultural. A este propósito, John Skorupski defende que se Mill permaneceu "bem mais democrata" do que outros autores que viram também este problema, como Tocqueville e Jacob Burkhardt, ele não deixou de ter uma visão moderada sobre o potencial de realização da democracia, em termos mais imediatos, não abdicando, no entanto, de acreditar nas possibilidades de todos os seres humanos desenvolverem as suas faculdades superiores (Skorupski, 2003: 186).

Esta abordagem não é muito diferente daquela que o levou a defender, nos Princípios de Economia Política, a intervenção do Estado, limitando, assim, o laissez-faire, laissez-passer. Aí, Mill considera que o consumidor nem sempre é o melhor juiz da mercadoria, assim como a opinião dos ignorantes não pode ser considerada suficientemente competente em matéria de cultura. Deste modo, ele admite que existem aspectos da vida que não podem reger-se unicamente pelo critério da competência de escolha dos indivíduos e que há aspectos da vida social que não podem funcionar nos mesmos moldes da economia de mercado (Mill, 1943: 804-836).

Um dos exemplos apresentados é o caso da educação cuja utilidade não pode ser equiparada a um uso quotidiano dos produtos correntes de consumo e cuja necessidade é tanto menos sentida quanto maiores forem as carências dos seus utilizadores. Em situaçóes como estas, ou quando as pessoas não estão em condiçóes de julgar a favor do seu próprio interesse $e^{51}$, ou ainda em momentos em que o mercado apresenta distorçóes, o Estado deve poder intervir.

Este facto leva mesmo Slavo Splichal a defender que John Stuart Mill está longe de corresponder à ideia comummente aceite que atribui ao filósofo a responsabilidade da noção de «livre mercado das ideias», uma expressão que, aliás, não se encontra em nenhum dos seus textos e é contrária à defesa que faz da intervenção do Estado na vida económica e social.

Mill é um claro defensor da liberdade de imprensa e da liberdade de expressão, tendo sido detido pela distribuição de textos considerados contra a moral pública - em causa estava um texto sobre a adopção de métodos contraceptivos. Para além disso, bateu-se contra a prisão de Richard Carlisle e da sua família por causa da publicação de textos contra a Igreja e de artigos de Thomas Paine, outro autor perseguido pelas suas ideias sobre a política e a religião. No entanto, nem por isso ele deixa de pensar a imprensa como uma liberdade que implica também a liberdade dos outros e, nesse sentido, considera que ela está sujeita a algumas regras. Por isso, ele defendeu a necessidade de os limites à liberdade

$51 \mathrm{~J}$. S. Mill refere-se às crianças, às pessoas mentalmente inaptas e, ocasionalmente, às mulheres. 
estarem devidamente regulados pela lei, como de resto tentou defender seu pai, James Mill, em Inglaterra, ou, em França, Condorcet, de modo a não permitir a livre interpretação dos poderes político e judicial sobre o que pode ou não ser escrito e publicado ou o que deve ser considerado ofensivo da moral e da ordem pública. No entanto, o direito pode ser também visto tanto como uma defesa da liberdade dos sujeitos face ao poder despótico como ao poder das maiorias.

Com efeito, para Mill, a liberdade de imprensa e a liberdade de expressão continuam ao serviço da realização do projecto iluminista da racionalidade pública. Mas para que isso possa acontecer, é preciso que o ponto de vista de cada um dos seus sujeitos possa ser escutado e não se veja silenciado pela indiferença. É também nesta linha de pensamento que o vemos a defender que a liberdade de expressão esteja submetida a regras de discussão de acordo com princípios éticos bem definidos, nomeadamente evitando: a deturpaçáo deliberada das ideias; a omissão de factos, argumentos ou descrição enganosa da opiniáo do outro; o desrespeito das opinióes minoritárias; a estigmatizaçáo dos que pensam diferente; e o uso da linguagem insultuosa (Mill, 1997: 56 e ss).

Para Mill, estas regras - que devem presidir a toda a discussão, e que de alguma forma chamam a atenção para a necessidade de uma ética comunicativa da discussão pública destinam-se a proteger as opiniốes minoritárias perante o que ele considera ser a tendência de as maiorias se dotarem de vantagens injustas (Mill 1997, 57) no debate público. Assim, estamos a falar de regras entendidas como formas de defesa contra o sectarismo social e o silenciamento de uma crítica lúcida. Este argumento leva mesmo Kevin C. O’ Rourke a defender que a defesa da individualidade é a questão central do livro Sobre a Liberdade, mais do que a liberdade de expressão ou a própria ideia de verdade. Para o comentador de John Stuart Mill, este aspecto coloca-nos perante um tipo diferente de utilitarismo uma vez que, antes de ser um procedimento para permitir a expressão do bem-estar da maioria, a liberdade de expressão é um instrumento essencial para garantir a própria realização dos sujeitos (O’Rourke, 2001: 163).

\section{Conclusáo}

Apesar de ambos serem defensores da liberdade de imprensa e da liberdade de expressão, Bentham e Mill têm duas concepçôes bastante diferentes acerca da sua realização. Se para Bentham a imprensa constitui um elemento fundamental para o exercício do tribunal da opinião pública contra os abusos do poder, para Mill a liberdade de imprensa continua bastante ligada a uma forma de expressão - uma liberdade de expressão por outros meios -, enquanto garante da realização dos sujeitos e, dentro do espírito iluminista, enquanto reserva do espaço crítico do progresso das sociedades.

Estas duas dimensóes do pensamento utilitarista, aqui reduzido ao pensamento de Mill e Bentham, antecipam uma evolução maior que o jornalismo se prepara para conhecer nesta altura e que marcará o início do denominado jornalismo moderno. A transformação dos leitores de jornais em públicos, a industrialização da imprensa, o desenvolvimento dos meios de comunicação, a profissionalização do jornalismo e a criação dos profissionais da informação acentuarão a dimensão instrumental do jornal e do jornalismo ao serviço da causa pública da informação, em detrimento da sua função crítica.

Se o pensamento e os princípios utilitaristas de Bentham marcaram os pressupostos da liberdade de imprensa até à primeira metade do séc. XX, as noções de livre circulaçáo e de 
livre mercado das ideias impuseram-se, sobretudo, a partir da II Guerra Mundial. Mas o que restou dessa liberdade foi a sua versão essencialmente empresarial e mercantilizada dos conteúdos e da liberdade de iniciativa (Splichal, 2004) mas que, à sua maneira, não deixa de continuar a pensar nas audiências como instrumentos de realização de negócios, quer visando atingir os públicos, quer procurando responder aos objectivos das minorias, entendidas, agora, como nichos de mercado. Porém, quer num caso quer noutro, a componente crítica e o respeito da individualidade surgem fortemente secundarizados, transformando frequentemente o livre mercado das ideias num mercado livre de ideias. Por mais que Mill possa ser associado à realização desse ideal de livre mercado das ideias, nada estará mais distante do seu pensamento do que as consequências e as lógicas silenciadoras desse mercado.

\section{Bibliografia}

BENTHAM, Jeremy, (2007), «Déclaration des droits de l'homme», in: BINOCHE, Bertrand, e CLÉRO, JeanPierre, Bentham Contre les Droits de l'Homme, Paris, Presses Universitaires de France.

BENTHAM, Jeremy, $\left(2001^{\mathrm{a}}\right)$, «Sur la liberté de la presse et de la discussion publique», in: BENTHAM, Jeremy, Garanties Contre L'Abus de Pouvoir et Autres Écrits Sur la Liberté Politique, Paris, Editions Rue d'ULM.

BENTHAM, Jeremy, (2001b), "Garantie contre l'abus de pouvoir», in: BENTHAM, Jeremy, Garanties Contre L'Abus de Pouvoir et Autres Écrits Sur la Liberté Politique, Paris, Editions Rue d'ULM.

CAMPONEZ, Carlos, (2010), Fundamentos de Deontologia do Jornalismo - A auto-regulação frustrada dos jornalistas portugueses (1974-2007), Tese de Doutoramento defendida na Universidade de Coimbra.

GOODWIN, H. Eugene, (1993), Procura-se Ética no Jornalismo, Rio de Janeiro, Editorial Nórdica.

MADEIRA, Pedro, (2006), «Introdução», in: MILL, John Stuart, Sobre a Liberdade, Lisboa, Ediçôes 70.

MANENT, Pierre, (1987), Histoire Intellectuelle du Libéralisme, s.l. Calmann-Lévy.

MILL, John Stuart, (1999), "Bentham (1838)», in: AUDARD, Catherine, Anthologie Historique et Critique de l'Utilitarisme - L'utilitarisme victorien (1839-1903), vol. II., Paris, Presses Universitaires de France.

MILL, John Stuart, (1943), Principios de Economia Política - Con algunas de sus aplicaciones a la filosofia social, México, Fundo de Cultura Económica.

MILL, John Stuart, (1997), Sobre a Liberdade, Mem Martins, Europa-América.

MILL, John Stuart, (2005), Utilitarismo, Lisboa, Gradiva.

MIRABEAU, (1992), De la Liberté de la Presse - 1788, Caen, Centre de Philosophie Politique et Juridique de L'Université de Caen.

O'ROURKE, C. Kevin, (2001), John Stuart Mill and Freedom of Expression - The genesis of a theory, Londres, Nova Iorque, Routledge.

SPLICHAL, Slavko, (2004), "Why are the rights of media owners considered superior to the personal right to communicate?», Media Development, n. ${ }^{\circ}$, URL: http://www.waccglobal.org/es/20042-citizenship-identitymedia/508-Why-are-the-rights-of-media-owners-considered-superior-to-the-personal-right-to-communicate. html, (05/10/2009).

SPLICHAL, Slavko, (2002), Principles of Publicity and Press Freedom, Lanham, Boulder, Nova Iorque, Oxford, Rowman \& Littlefield Publishers.

SKORUPSKI, John, (2003), "John Stuart Mill», in: CONTE-SPERBER, Monique, Dicionário de Filosofia Moral, vol. 2, São Leopoldo, Unisinos.

TRENCHARD, John, e GORDON, Thomas, (1995), "Of freedom of speech: That the same is inseparable from public Liberty", in:TRENCHARD, John, e GORDON, Thomas, Cato's Letters - Or Essays on liberty, civil and religious, and other important subjects, vol. I, Indianapolis, Liberty Fund.

WARD, Stephen J. A., (2004), The Invention of Journalism Ethics - The path to objectivity and beyond, Montreal, Londres, Ithaca, McGill-Queen's University Press. 


\section{NotAS BIOGRÁFICAS DOS AUTORES}

\section{Alexandre Franco de Sá}

Alexandre Franco de Sá é Professor Auxiliar no Departamento de Filosofia, Comunicação e Informação da Faculdade de Letras da Universidade de Coimbra, sendo actualmente Director do Curso de Licenciatura em Filosofia. Tem publicado regularmente nas áreas da Ética, da Filosofia Política e da Fenomenologia e traduzido obras de autores como Johann Fichte, Martin Heidegger, Eric Voegelin, Ernst Jünger e Carl Schmitt. É actualmente Presidente da Associação de Professores de Filosofia. Página pessoal: http://sites.google.com/ site/alexandrefrancosa/

\section{Ana Teresa Peixinho}

Ana Teresa Peixinho é Professora Auxiliar da Faculdade de Letras da Universidade de Coimbra, onde, em 1996, concluiu o mestrado em Literatura Portuguesa Moderna, com a apresentação da dissertação $A$ Génese da Personagem Queirosiana em Prosas Bárbaras, publicada pela Editora Minerva em 2002. Doutorou-se em 2008, em Ciências da Comunicação, pela Faculdade de Letras da Universidade de Coimbra. Publicou pela INCM duas ediçóes críticas de obras de Eça de Queirós. Participou em diversos colóquios e congressos, com comunicaçóes no domínio dos estudos queirosianos, bem como no domínio da História da Imprensa e da Análise do Discurso. É investigadora do CEIS20.

\section{Carlos Camponez}

Carlos Camponez Professor Auxiliar da Faculdade de Letras da Universidade de Coimbra. Docente de Ética e Deontologia, Sócio-Economia dos Media e foi membro do Conselho Deontológico do Sindicato dos Jornalistas (2008-2010). Jornalista free-lance e ex-jornalista do Diário de Lisboa, A Capital, Público, Jornal de Leiria e Regiáo de Leiria. Acompanha de perto as questóes relacionadas com a imprensa regional, sobre a qual defendeu a tese de mestrado, e da deontologia e auto-regulação dos jornalistas, tema da sua tese de doutoramento.

\section{Diogo Pires Aurélio}

Professor de Filosofia Política na Universidade Nova de Lisboa e investigador do Instituto de Filosofia da Linguagem, responsável pela área de Ética e Filosofia Política. Coordena actualmente o projecto "Global Justice and International Terrorism», financiado pela FCT.

Publicou várias obras no domínio da Filosofia, entre as quais Um fio de nada, ensaio sobre a tolerância (1997, 2010), A vontade de sistema (1998), Imaginação e poder, estudo sobre a filosofia política de Espinosa (2000), Razão e Violência (2007), Representação Política (2009). Traduziu e prefaciou ediçôes de Maquiavel, O Príncipe (2008), Espinosa, Tratado Teológico-Politico (1988, 2003, 2004, 2008), Tratado Político (2008, 2009) e Richelieu, Testamento Político (2008). Prefaciou a edição portuguesa do livro de Jacques Rancière, $O$ ódio à democracia (2007).

Foi director da Radiodifusão Portuguesa, administrador da INCM, presidente da Comissão Nacional da UNESCO e Director da Biblioteca Nacional.

Recebeu, em 2009, o Prémio de Tradução Científica e Técnica da União Latina/FCT, pela tradução do Tratado Político, e uma menção honrosa pela tradução de $O$ Príncipe. 


\section{Jónatas Eduardo Mendes Machado}

Professor Associado da Faculdade de Direito da Universidade de Coimbra. Autor de várias obras jurídicas na área do direito público. Director Executivo do Centro de Direitos Humanos do Instituto «Ius Gentium Conimbrigae» da Faculdade de Direito da Universidade de Coimbra. Obteve o grau de Mestre com a dissertação "Liberdade Religiosa numa Comunidade Constitucional Inclusiva» e o grau de Doutor com uma dissertação intitulada "Liberdade de Expressão». Teve a oportunidade de participar nas efemérides dos 400 anos do nascimento de Roger Williams e de John Milton, por muitos considerados, respectivamente, o pai da liberdade religiosa e o pai da liberdade de expressáo.

\section{José Tomaz Castello Branco}

José Tomaz Castello Branco é doutorado Ciência Política e Relaçóes Internacionais, pela Universidade Católica Portuguesa. É Professor Auxiliar Convidado no Instituto de Estudos Políticos da UCP, onde lecciona Teoria Política Contemporânea, Regimes e Sistemas Políticos e História do Pensamento Político. As suas áreas de investigação, centradas no âmbito da teoria política contemporânea, incluem áreas distintas como as do pluralismo de valores, liberdade e tolerância, utopismo, terrorismo e pensamento político islâmico contemporâneo.

\section{Manuel Alegre}

Manuel Alegre fez da liberdade um dos temas principais da sua vida enquanto político, escritor e poeta. Nasceu em Águeda, em 1936, numa família de tradição liberal e republicana. Estudante de Direito em Coimbra, a sua tomada de posiçáo sobre a ditadura e a guerra colonial levam o regime de Salazar a chamá-lo para o serviço militar em 1961, sendo colocado nos Açores, onde tenta uma ocupação da ilha de S. Miguel, com Melo Antunes. Em 1962 é mobilizado para Angola, onde dirige uma tentativa pioneira de revolta militar. É preso pela PIDE em Luanda, em 1963. Um ano mais tarde, depois de um breve regresso a Coimbra, parte para o exílio, na Argélia, de onde só voltou em Maio de 1974. Autor de uma vasta e reconhecida produção poética, iniciada com Praça da Canção em 1965, Alegre faz da poesia uma arma de combate em prol da igualdade, da liberdade e da intervenção cívica. Na sua obra encontramos também vários romances e livros infantis. Foi Prémio Pessoa em 1999. A sua obra mais recente é de 2010: O miúdo que pregava pregos numa tábua.

\section{Maria João Silveirinha}

Maria João Silveirinha é doutorada em Ciências de Comunicação, pela Universidade Nova de Lisboa. É Professora Associada da Secção de Comunicação do Departamento de Filosofia, Comunicação e Informação da Faculdade de Letras da Universidade de Coimbra, onde lecciona matérias ligadas à comunicação, à investigação dos media e aos estudos de género. Os seus interesses de investigação centram-se no tema das relaçóes entre as identidades e a comunicação como medium das interacçôes sociais. É neste sentido que tem investigado particularmente os temas dos direitos comunicativos das mulheres. É autora de vários livros e artigos científicos neste domínio. 